\title{
RESEARCH PAPER \\ STORAGE ROT FUNGI AND SEED-BORNE PATHOGENS OF ONION
}

\author{
B. A. Adongo ${ }^{1}$, C. K. Kwoseh ${ }^{1} *$ and E. Moses $^{2}$ \\ ${ }^{I}$ Department of Crop and Soil Sciences, KNUST, Kumasi, Ghana. \\ ${ }^{2}$ Plant Health Division, CSIR-Crop Research Institute, Fumesua, Kumasi, Ghana. \\ *Corresponding author: ckwoseh@hotmail.com or ckwoseh.canr@knust.edu.gh
}

\begin{abstract}
Surveys of fungi associated with postharvest deterioration of onion bulbs in four major markets in Kumasi Metropolis of the Ashanti Region of Ghana were conducted. Rotten onion bulbs obtained from the four markets (Abinchi, Anloga, Kwadaso and Central markets) were infected by five fungal species: Aspergillus niger, A. flavus, Penicillium sp., Rhizopus stolonifer and Fusarium oxysporum. Of these, A. niger and Penicillium sp. were the most frequently isolated fungi. A. flavus was the least encountered fungus. $R$. stolonifer and A. niger were the most pathogenic. Black mould, blue mould, soft rot, neck rot and basal plate rot were the major storage rots identified in a dry season survey in the markets. Incidences of these storage rots were higher in the wet season. Black mould enjoyed the highest incidence in all markets. Using the moist blotter method as recommended by the International Seed Testing Association (ISTA), seed-borne mycoflora of 37 samples of farmer-saved onion seeds from Bawku in the Upper East Region of Ghana were also examined. Nine different fungal species were identified and isolated from the seeds viz. A. niger, A. flavus, Penicillium sp., $R$. stolonifer, Fusarium oxysporum, Fusarium verticilloides, Fusarium poae, Alternaria porri and Botrytis sp. The most frequently encountered fungi were A. niger, $R$. stolonifer, A. flavus, Penicillium sp. and F. verticilloides with the occurrence of 33.3, 32.5, 25.8, 3.1 and 3.0\%, respectively. The postharvest disease with the highest incidence in all the four markets surveyed was black mould. Some seed-borne fungi of onion were found to be associated with the onion bulb rots. Therefore, infected onion seeds could serve as inoculum source of the postharvest diseases of onion and contribute to the rot of bulbs during storage. In general, practices such as rotation, sanitation, optimum fertilization, preventive chemical applications, harvest timing and proper handling, harvesting, and storage are recommended for onion disease management.
\end{abstract}

Keywords: Post-harvest, seed-borne, mycoflora, pathogenic, fungi

\section{INTRODUCTION}

Onion (Allium cepa L.) is one of the most important vegetable crops grown in Ghana. Com- mercial production is done in the Northern and Upper East Regions especially, around Bawku and Bolgatanga. Intense onion production is 


\section{Adongo et al.}

also found in the Kwahu South District, Mankessim and Berekum areas of southern Ghana (Norman, 1992).

Onion is cultivated for its pungent or mild flavours and forms an essential ingredient in the diet of many people. The distinctive characteristic of onion is due to the presence of alliaceous odour which accounts for its use as food, salad, spices, condiment and in medicine (Raju and Naik, 2007). According to Norman (1992), onion is relatively high in food value, intermediate in protein, rich in calcium and riboflavin.

However, the storage life of this essential vegetable crop in our daily diet, according to Currah and Proctor (1990), is affected by several factors including sprouting, drying and rotting. Bulb rotting, particularly, caused by fungal species, causes severe losses during storage. Losses as high as $60 \%$ during storage due to moulds have been reported (Tanaka, 1991). Losses in the range of $10-50 \%$ due to bulb rot could occur during storage within three months when varieties susceptible to rot organisms are handled (Matthananda, 1992).

Observations in Ghanaian markets and homes indicate that, losses due to microbial attacks could be higher than what have been reported by other workers because of poor conditions under which onions are stored. Also the onion farmers in Ghana, particularly those around Bawku and Bolgatanga, use their own saved and possibly contaminated seeds for cultivation. Therefore, like any other seeds, the onion seeds can serve as a source of inoculum for disease development in the field and later during storage of the bulbs. Onion production, according to El-Nagerabi and Ahmed (2003), is limited by fungal infections which cause considerable pre- and post-harvest losses that are largely seed-borne. It is, therefore, expected that various pathogenic fungi would be associated with onion seeds and can contribute to the rotting of bulbs during storage.
Despite the losses from onion bulb rot and seed -borne pathogens, little studies have been done in Ghana to identify the fungal genera or species responsible for the storage rots and the possible contribution of the onion seeds to these rots. The objectives of this study, therefore, were to identify seed-borne fungal pathogens of onion and those associated with storage rot of onion bulbs in some markets within the Kumasi Metropolis and to also determine the incidence of the storage rots in those markets.

\section{MATERIALS AND METHODS}

Surveys on incidence of onion storage rots (postharvest diseases) in four selected markets in the Kumasi Metropolis

Two surveys were carried out in four selected markets in the Kumasi Metropolis, namely Central, Anloga, Kwadaso and Abinchi to sample and document the incidence of onion postharvest diseases. The surveys were done separately, in the dry season (January-February) and in the wet season (June-July). At each market, 50 onion bulbs were selected randomly from 10 onion traders and the type of diseases or rot (blemish) on each bulb recorded after careful visual observation of symptoms on the selected bulbs. The percentage disease incidence for each disease was determined by using the formula in Raju and Naik (2007) stated below:

$$
\text { Pencont diseoss imcidmos }=\frac{\text { number of inf octed buibs }}{\text { tstai numbry of bulbs }} \times 100
$$

\section{Collection of onion samples}

The onion bulbs showing symptoms of rot and discolouration that were randomly sampled from various traders in four major markets were brought to the Plant Pathology Laboratory of the Council for Scientific and Industrial Research - Crops Research Institute, Kumasi, for microbial or pathological analysis.

\section{Preparation of potato dextrose agar (PDA) for isolation of fungi}

Two hundred grammes $(200 \mathrm{~g})$ of peeled potato, $20 \mathrm{~g}$ of glucose, $20 \mathrm{~g}$ of agar and one litre (1L) 
of distilled water were used to prepare PDA. The peeled potato tubers were cut into pieces with a sterile knife, weighed, washed and boiled in $500 \mathrm{ml}$ of the distilled water. The potato was then mashed in the boiling water and sieved three times through cheesecloth to obtain the potato extract. The $20 \mathrm{~g}$ of glucose was then added to the potato extract and stirred thoroughly, using a magnetic stirrer. The agar was then melted in the potato-glucose mixture in a beaker and was then topped with distilled water to a litre full. The PDA was sterilised in an autoclave at $121^{\circ} \mathrm{C}$ for $20 \mathrm{~min}$. It was left to cool to about $45^{\circ} \mathrm{C}$ and was dispensed into sterilised Petri dishes.

\section{Isolation and identification of rot-inducing fungi from infected onion bulbs}

The infected bulbs were stripped of their outer dry scales and small pieces of the infected onion bulbs were removed with a sterile knife and surface sterilised in $1 \%$ bleach for one minute. The pieces of the scale tissues were then rinsed three times in sterile distilled water and allowed to dry in a sterile laminar flow cabinet. The scales were plated on PDA in $90 \mathrm{~mm}$ diameter sterilised Petri dishes and incubated at $28^{\circ} \mathrm{C}$ for seven days in an incubation room. The developing fungal colonies were sub-cultured on fresh PDA plates to obtain pure cultures. The fungal isolates were identified based on their cultural and morphological characteristics including shapes of spores or conidia (Barnett and Hunter, 1998). The frequency of isolation of each fungal species was recorded. The occurrence was calculated using the following formula (Ilondu, 2011):

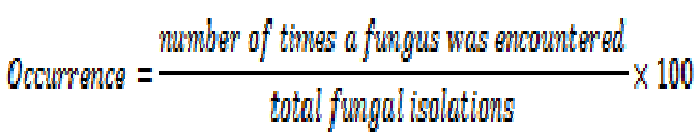

Pathogenicity test using fungal isolates

Fresh healthy onion bulbs were removed of their outer dry scales. The inner fresh scales were swabbed with cotton wool soaked in $70 \%$ ethanol aseptically. Holes were made in the bulbs, using $3 \mathrm{~mm}$ diameter sterile cork-borer and the tissue plugs were pulled out and ex- changed with $3 \mathrm{~mm}$ diameter mycelial disc of each of the cultured isolated fungi. The fungal disc was inserted into the hole created and onion plug placed back. The wounded area was sealed with sterile Vaseline to prevent extraneous infections. The bulbs were incubated for four weeks at $28^{\circ} \mathrm{C}$ in the incubation chamber. Three replications containing two bulbs were prepared for each treatment. The control consisted of sterilised 3mm PDA disc placed in holes made in healthy bulbs. Observation for rot development (symptoms) was made and the degree of pathogenicity of each fungus determined by measuring the extent of the rot $(\mathrm{mm})$ on the inoculated bulbs with a ruler (Shehu and Muhammad, 2011).

\section{Seed health test}

Bawku Red seeds were collected from 37 farmers at Bawku in the Upper East Region of Ghana. The farmer-saved onion seeds were used for the seed health test, which was conducted, using the Standard Blotter Method (Mathur and Kongsdal, 2003). The seed-borne fungal infections were determined by plating 400 seeds from each of the 37 seed samples on moistened three-layer filter paper to provide enough moisture in the Petri dishes. Each Petri dish contained 25 seeds. The plates were incubated for seven days at $25 \pm 2^{\circ} \mathrm{C}$ in alternating cycles of $12 \mathrm{~h}$ near ultraviolet light (NUV) and darkness. The seeds were then examined for fungal infection in accordance with Mathur and Kongsdal (2003). Identification of fungi based on their habit characters and morphological characteristics was done, using laboratory manuals, stereo and compound microscopes. Sub-culturing for pure cultures of some of the fungal isolates was done as and when necessary for proper and accurate identification. The mean percentage of isolations for each fungus was based on 400 seeds.

\section{RESULTS}

A total of four fungal genera and five species, namely Aspergillus niger, A. flavus, Penicillium sp., Rhizopus stolonifer and Fusarium oxysporum were isolated from the infected onion 
bulbs collected from the selected markets (Abinchi, Central, Anloga and Kwadaso) in the Kumasi Metropolis (Table 1).

A. niger recorded the highest frequency of isolation (35.0\%), followed by Penicillium (27.0\%), then R. stolonifer $(14.5 \%)$ and F. oxysporum $(14.5 \%)$, with $A$. flavus recording the least, $9.0 \%$ (Table 1).

In the dry and wet seasons survey of the markets to determine the incidence of post-harvest diseases of onion, five post-harvest diseases were encountered and they were black mould, blue mould, soft rot, neck rot and basal plate rot (Table 2). All the markets recorded very low incidences of the post-harvest diseases (Table 2) with the exception of Abinchi market that had $16.2 \%$ for black mould. The most predominant disease during the dry season survey was black mould, followed by basal plate rot, then neck rot, soft rot and the least, blue mould (Table 2).

The wet season recorded increases in postharvest diseases at the various markets (Table 2) as compared to the dry season. Anloga market recorded the highest incidence of black mould and neck rot diseases of $31.3 \%$ and $12.6 \%$, respectively (Table 2). Similarly, Abinchi market recorded the highest incidence $(32.3 \%)$ of soft rot and the Central market recorded the highest incidence of basal plate rot $(7.8 \%)$. In all the four markets surveyed, black mould was the most predominant $(26.7 \%)$ followed by soft rot $(23.9 \%)$, neck rot $(11.0 \%)$,

Table 1: Occurrence of isolated fungi associated with storage rots of onion bulbs for the selected markets

\begin{tabular}{ll}
\hline Fungus & Frequency of isolation from rotten bulbs (\%) \\
\hline Aspergillus niger & 35.0 \\
Aspergillus flavus & 9.0 \\
Penicillium sp. & 27.0 \\
Rhizopus stolonifer & 14.5 \\
Fusarium oxysporum & 14.5 \\
\hline
\end{tabular}

Table 2: Incidence of storage rots (post-harvest diseases) of onion in four markets in Kumasi Metropolis during the dry and wet seasons

\begin{tabular}{lcccccccccc}
\hline & \multicolumn{1}{c}{} & \multicolumn{4}{c}{ Post-harvest disease incidence (\%) } & \multicolumn{3}{c}{ Bock rot } & \multicolumn{2}{c}{ Basal plate rot } \\
Market & Dry & Wet & Dry & Wet & Dry & Wet & Dry & Wet & Dry & Wet \\
\hline Abinchi & 16.2 & 22.5 & 0.2 & 2.0 & 1.8 & 32.3 & 3.0 & 10.4 & 8.2 & 6.0 \\
Central & 6.0 & 25.2 & 0.2 & 3.0 & 2.8 & 28.2 & 2.8 & 11.4 & 1.0 & 7.8 \\
Anloga & 1.6 & 31.3 & 0.0 & 2.1 & 0.6 & 17.0 & 2.0 & 12.6 & 0.2 & 5.3 \\
Kwadaso & 0.6 & 27.7 & 0.2 & 1.2 & 2.4 & 18.0 & 0.2 & 12.0 & 0.2 & 6.8 \\
Mean & $\mathbf{6 . 1}$ & $\mathbf{2 6 . 7}$ & $\mathbf{0 . 2}$ & $\mathbf{2 . 1}$ & $\mathbf{1 . 9}$ & $\mathbf{2 3 . 9}$ & $\mathbf{2 . 0}$ & $\mathbf{1 1 . 6}$ & $\mathbf{2 . 4}$ & $\mathbf{6 . 5}$ \\
\hline
\end{tabular}


basal plate rot $(6.5 \%)$ and the lowest incidence of $2.1 \%$ caused by blue mould (Table 2 ).

For the experiment to establish pathogenicity of isolated fungi, the greatest growth (rot) diameter was recorded for $R$. stolonifer $(43.0 \mathrm{~mm})$ in 21 days when bulbs of Bawku Red were incubated. The minimum growth (rot) diameter of $16.0 \mathrm{~mm}$ was recorded for Penicillium sp. (Table 3).

Nine different fungal species were isolated from farmer-saved seeds collected from Bawku, Upper East Region. These fungal species were A. niger, A. flavus, Penicillium sp., $R$. stolonifer, $F$. oxysporum, $F$. verticilloides, $F$. poae, Alternaria porri and Botrytis sp. (Table
4). The frequently isolated fungi were $A$. niger, $R$. stolonifer, A. flavus, Penicillium sp. and $F$. verticilloides with frequency of isolation of $33.3,32.5,25.8,3.1$ and $3.0 \%$, respectively. The least encountered were Alternaria porri and Botrytis sp., $(0.2 \%)$ each (Table 4$)$.

\section{DISCUSSION}

Onion bulbs, being perishable, contain about $86.8 \%$ of moisture and form an ideal medium for proliferation of many storage fungi (Srinivasan et al., 2002). The study revealed that $A$. niger, $R$. stolonifer, $F$. oxysporum, $A$. flavus and Penicillium sp. were associated with onion bulb rot from the major markets in the Kumasi Metropolis. This finding is in conformity with that of Shehu and Muhammad

Table 3: Pathogenicity of isolated fungi on onion bulbs determined by the diameter of rot after 21 days of incubation

\begin{tabular}{ll}
\hline Treatment & Diameter of rot on onion bulb (mm) \\
\hline Aspergillus niger & 40.0 \\
Aspergillus flavus & 21.0 \\
Penicillium sp. & 16.0 \\
Rhizopus stolonifer & 43.0 \\
Fusarium oxysporum & 37.0 \\
Sterilised 3mm-PDA disc (Control) & 12.0 \\
\hline
\end{tabular}

Table 4: Occurrence of fungi on onion seeds from Bawku

\begin{tabular}{ll}
\hline Fungus & Occurrence (\%) \\
\hline Aspergillus niger & 33.3 \\
A. flavus & 25.8 \\
Penicillium sp. & 3.1 \\
Rhizopus stolonifer & 32.5 \\
Fusarium oxysporum & 0.7 \\
Fusarium verticilloides & 3.0 \\
Fusarium poae & 1.2 \\
Alternaria porri & 0.2 \\
Botrytis sp. & 0.2 \\
\hline
\end{tabular}


(2011) who also isolated the above five fungi species from rotten onion bulbs in addition to A. fumigates and Alternaria porri also from the onion bulbs.

Ara et al. (2008) also isolated A. niger, F. oxysporum, A. flavus and Penicillium sp. from rotten bulbs of five varieties of onion in Bangladesh. Tyson and Fullerton (2004) reported Aspergillus sp. that causes black mould as the major isolate from rotten onions. These fungi, in most reports, cause severe losses such that as high as $35 \%$ losses have been reported to be caused by F. oxysporum (Christopher, 2000).

A. niger had the highest frequency of isolation. This is in line with the findings of Ko et al. (2002) who reported that black mould caused by $A$. niger is the major disease during storage under ambient conditions in the tropics. $R$. stolonifer recorded the highest rot on the bulbs and this agrees with the observation by Shehu and Muhammad (2011) who reported that $R$. stolonifer was one of the most pathogenic fungi leading to rapid disintegration of the infected onion bulbs. A. niger also had a greater rot on the onion bulbs. This observation, however, contrasts the findings of Shehu and Muhammad (2011).

From the study, black mould, neck rot, blue mould, soft rot and basal plate rot were the most important post-harvest diseases of onion identified. Among these post-harvest diseases, black mould was the most predominant disease in both the dry and wet seasons. Raju and Naik (2007), in a similar survey, identified the same diseases as the important post-harvest diseases of onion in Karnataka, India. Ko et al. (2002) and Musah et al.(1973) reported that black mould is a major rot disease when onions are stored under ambient temperatures and therefore, corroborates these findings.

All the post-harvest diseases encountered were caused by fungi when isolations were done and identified, except the soft rot which is caused by bacteria. This finding agrees with the obser- vation made by Padule et al. (1996) that fungi are the major causal agents responsible for storage losses of onion bulbs.

In general, there was an increase in all the postharvest diseases during the wet season probably because of high relative humidity. This observation, according to Raju and Naik (2007), is due to favourable temperatures and high relative humidity during the wet season.

The fungal isolates; A. niger, A. flavus, $R$. stolonifer, Penicillium sp., F. oxysporum, $F$. verticilloides, $F$. poae, Alternaria porri and Botrytis sp. were the major fungal species isolated and identified on the onion seeds of Bawku Red variety. Aveling et al. (1993) isolated the same fungi above from infected seeds of onions in South Africa. A. niger was the most encountered fungi among the onion seeds tested. This corroborates the findings of ElNagerabi and Abdalla (2004) that Aspergillus was the frequently encountered genus from the onion seeds examined in Sudan. The high prevalence of $A$. niger on the seeds could be attributed to its ability to utilize the vulnerability of the flowers to penetrate the onion seeds (Sirois and Lorbeer, 1998).

Among all the fungi isolated from onion seeds, not all of them are known to be important pathogens in the transmission of onion diseases. Seedborne infections are relevant only if the infected seeds germinate and transmit the pathogens to the plant which acts as primary disease source in crops (Neergaard, 1979; Maude,1980). Nevertheless, some of these fungi are pathogens of known onion diseases. For instance, A. niger, in severe cases, prevents the development of root and shoot due to preemergence damping-off (Gupta and Mehra, 1984); it also reduces seed germination, seedling emergence and vigour (Koycu and Ozer, 1997; El-Nagerabi and Ahmed, 2001). Hayden et al. (1994) observed that A. niger could also be transmitted from contaminated seeds to stored onion bulbs to cause Black mould diseases. Sumner (1995) reported that $R$. stolonifer 
on onion seeds cause mushy rot on bulbs, particularly, in the neck region. Botrytis sp. causes neck rot disease of onion and $F$. oxysporum causes basal plate rot and could be transmitted from seeds to onion sets (Koycu and Ozer, 1997). Suheri and Price (2000) have reported that Alternaria porri causes purple blotch of onions worldwide. According to Abd-El Razik et al. (1990), F. verticilloides is pathogenic and causes pre- and post-emergence damping-off of seedlings.

Some of these seed-borne pathogens such as $A$. niger, Botrytis sp. and $F$. oxysporum are also known causal agents of onion post-harvest diseases. The current results confirm the findings of Hayden et al. (1994) and Sumner (1995) that some seed-borne pathogens can be carried up to storage. Therefore, they contribute to postharvest diseases of onion. The role of the seeds as one of the major sources of fungal infections and disease development in onion production in Ghana, therefore, can not be over-emphasized.

\section{CONCLUSION}

Four genera with five fungal species, namely $A$. niger, A. flavus, Penicillium sp., R. stolonifer and $F$. oxysporum were associated with onion bulb rot in the four markets surveyed in the Kumasi Metropolis. Among these rot-inducing fungi, A. niger was the most frequently encountered pathogen. All the isolated rot-inducing fungi were found to be pathogenic to onion bulbs, with $R$. stolonifer being the most pathogenic.

Black mould, blue mould, soft rot, neck rot and basal plate rot incidences in the four major markets during the dry season were low, compared to the incidences of these diseases during the wet season survey. The post-harvest disease with the highest incidence in all the four markets surveyed was black mould. The seeds of Bawku Red were found to be infected with nine fungal species in six genera viz; A.niger, A. flavus, Penicillium sp., $R$. stolonifer, F. oxysporum, F. verticilloides, $F$. poae, Alternaria. porri and Botrytis sp. Among these seed-borne fungi of Bawku Red, A.niger was the most frequently encountered fungus and the least encountered were A. porri and Botrytis sp. Some of these seed-borne fungi of onion were also found to be associated with the onion bulb rots. Therefore, the infected onion seeds could serve as inoculum source of the postharvest diseases of onion and contribute to the rot of bulbs during storage. Onion diseases can cause severe losses by reducing yield and quality of marketable onions. These onion diseases can occur in seedbeds, production fields and storage. To manage onion diseases, practices such as rotation, sanitation, optimum fertilizer application, preventive fungicide/bactericide applications, harvest timing and proper handling, harvesting, and storage are recommended.

\section{REFERENCES}

Abd-El-Razik, A. A., Fahmy, F. G., Amein, A. M. and El-Amein, A. I. (1990). Role of onion seeds in transmission of damping off causal fungi and chemical control of the disease. Assiut Journal of Agricultural Sciences, 21 (1): 173-193.

Ara, M. A. H., Khatun, M. L. and Ashrafuzzaman, M. (2008). Fungi causing rot in onions at storage and market. Journal of Bangladesh Agricultural University, 6(2):245-251.

Aveling, T. A. S., Snyman, H.G. and Naude, S. P. (1993). Evaluation of seed treatments for reducing Alternaria porri and Stemphyliumvesicarium on onion seed. Plant Disease, 77 (10): $1009-1011$.

Barnett, H. L. and Hunter, B. B. (1998). Illustrated Genera of Imperfect Fungi. 4th edition. APS Press, St Paul, Minnesota.

Christopher, S. C. (2000). Breeding and genetics of Fusarium basal rot resistance in onion. Euphytica,115: 159 - 166.

Currah, L. and Proctor, F. J. (1990). Onion in tropical regions. Bulletin no. 35. Natural Resources Institute. Chatham, Maritime, Kent, 
UK.

El-Nagerabi, S. A. F and Ahmed, A. H. M. (2001). The effect of black mould Aspergillus niger) on two Sudanese cultivars of onion. Tropical Science, 41: 95 - 99.

El-Nagerabi, S. A. F and Ahmed, A. H. M. (2003). Storability of onion bulbs contaminated by Aspergillus niger mould. Phytoparasitica, 31:515-523.

El-Nagerabi, S. A. F and Abdalla, R. M. O. (2004). Survey of seedborne fungi of Sudanese cultivars of onion, with new records. Phytoparasitica,32(4):413-416.

Gupta, R. P. and Mehra, V. (1984).Studies on the effect of fungal metabolites on viability and seedling vigour of onion seed. Indian Journal of Plant Pathology, 2: 100 - 102.

Hayden, N. J., Maude, R. B. and Proctor, F. J. (1994). Studies on the biology of black mould (Aspergillus niger) on temperate and tropical onions 1 . A comparison of sources of disease in temperate and tropical field crops. Plant Pathology, 43: 562 -569.

Ilondu, E. M. (2011). Evaluation of aqueous plant extracts used in the control of pawpaw fruit (Carica papaya L.) rot fungi. Journal of Applied Biosciences, 37:2419-2424.

Ko, S., Huang, J., Wang, J., Subramanyam, S. and Chang, W. (2002). Evaluation of onion cultivars for resistance to Aspergillus niger, the causal agent of black mold. Journal of American Society of Horticultural Science, 127(4):697-702.

Köycü, N. D. and Ozer, N. (1997). Determination of seed-borne fungi of onion and their transmission to onion seeds. Phytoparasitica, $25: 25-31$.

Mathur, S. B and Kongsdal, O. (2003). Common Laboratory Seed Health Testing Meth- ods for Detecting Fungi. $1^{\text {st }}$ edition, Publisher; International Seed Testing Association.

Matthananda, K. A. (1992). Varietal evaluation for storability of big onion. Seasonal Report, Maha1991/1992, Agriculture Research Station. MahaIlluppallama.

Maude, R. B. (1980). Storage diseases of onions. In: H. D. Rabinowitch and J. L. Brewster (eds.), Onions and Allied Crops. CRC Press. Florida, USA. pp. 273 - 296.

Musah, S. A., Habish, H. A., Abdalla, A. A and Adlan, A. B. (1973). Problems of onion storage in Sudan. Tropical Science, 15:319-327.

Neergaard, P. (1979). Seed Pathology. Vol 1. The Macmillan Press, London.

Norman, J. C. (1992). Tropical vegetable crops. Arthur H. Stockwell Ltd. Ilfracombe, Great Britain.

Padule, D. N., Katecha, M., and Lohate, S. R., (1996). Fungi pathogens associated with spoilage of onion during storage. Onion News Letter for the Tropics. L. Currah and J. E. Orchard (eds.). Natural Resources Institute. Chatham, Maritime, Kent, UK.

Raju, K. and Naik, M. K. (2007). Survey and assessment for the post-harvest diseases of onion in North-Eastern Karnataka. Karnataka Journal of Agriculture Science, 20(1): 164-165.

Shehu, K. and Muhammad, S. (2011). Fungi associated with storage rots of onion onion bulbs in Sokoto. Nigeria. International Journal of Modern Biology, 1(1):1-3.

Sirois, K. L. and Lorbeer, J. W. (1998). Susceptibility of onion seed stalks and flowers to infection by Aspergillus niger Tiegh. In: Proceeding $7^{\text {th }}$ biennial National Onion (and 
Seed-borne fungal pathogens of onion ... 21

other Allium) Research Conference. California, December 10-12, pp. $353-360$.

Suheri, H. and Price, T. V. (2000). Infection of onion leaves by Alternaria porri and Stemphylium vesicarium and disease development in controlled environments. Plant Pathology, 49: $375-382$

Srinivasan, D., Perumalsamy, L. P., Nathan, S. and Sures, T. (2002). Antimicrobial activity of certain Indian medicinal plants used in folkloric medicine. Journal of Ethnopharmacology, 94: 217-222.

Sumner, D. R. (1995). Diseases of bulbs caused by fungi - Black mold. In: H. F. Schwartz and S. K. Mohan (eds.). Compendium of onion and garlic diseases. APS Press, St. Paul. Minnesota. pp. 26-27.

Tanaka, K. (1991). Studies on the black mould disease of onion bulbs caused by Aspergillusniger van Tieghem. Bulletin of Faculty of Agriculture. Saga University, 70: 1-54.

Tyson, J. L. and Fullerton, R. A. (2004). Effect of soil borne inoculum onion incidence of onion black mould (Aspergillus niger). New Zealand Plant Protection, 57:138-141. Proceedings of a conference, Hamilton, New Zealand, 10-12 August, 2004. 